\title{
A REFORMA DO MERCADO PÚBLICO: PRÁTICAS E MITOS DE FUNDAÇÃO DA CIDADE
}

Ana Luiza Carvalho da Rocha ${ }^{1}$

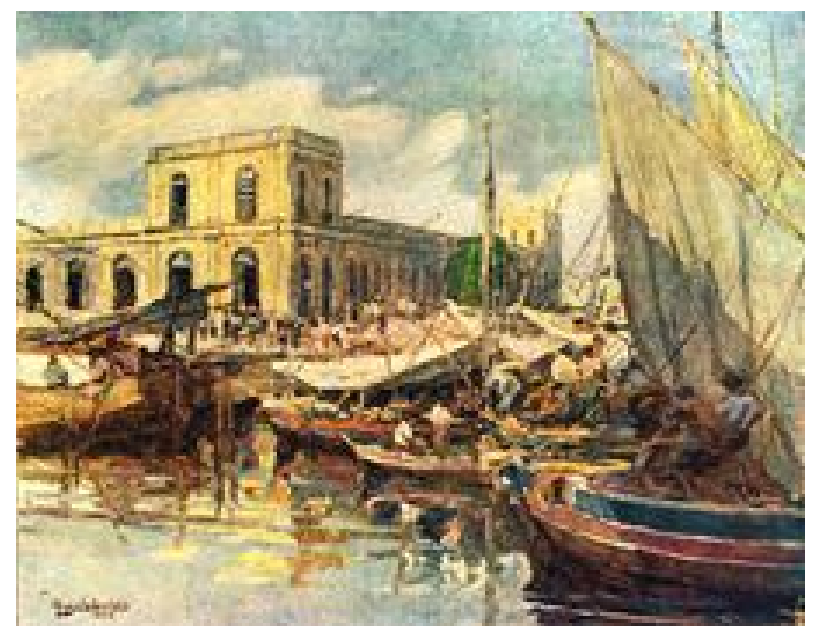

Tela: Pintura a óleo

Auto: Angelo Guido

Brasil, Arapongas, 1938, um antropólogo francês em visita ao Brasil e não se contendo diante do dinamismo das imagens do tempo que presidia o nascimento da cidade nos Trópicos, afirma que ali habitava um povo cujo trajeto da barbárie à decadência jamais havia conhecido a força da civilização.

Sem dimensão temporal, as grandes cidades industriais da América tropical dos anos 30 descortinavam-se aos olhos desse antropólogo como uma paisagem triste e devastada. À mercê dos mitos da ruína e do fracasso e sob a

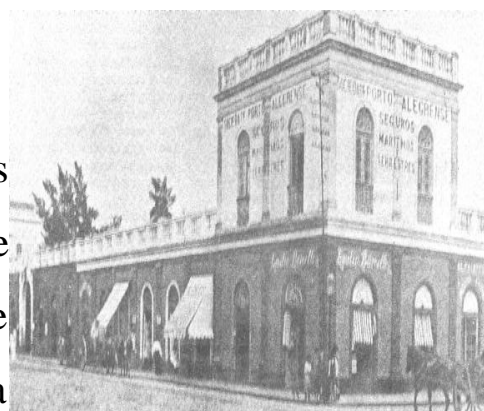
pressão de fábulas progressistas, as cidades nos Trópicos alimentariam-se vorazmente do novo, sem nenhum compromisso com o seu passado histórico.

\footnotetext{
${ }^{1}$ Artigo publicado no Jornal Zero Hora, 1998.
} 
Porto Alegre, antigo Largo do Mercado, 1997, sofrendo dos

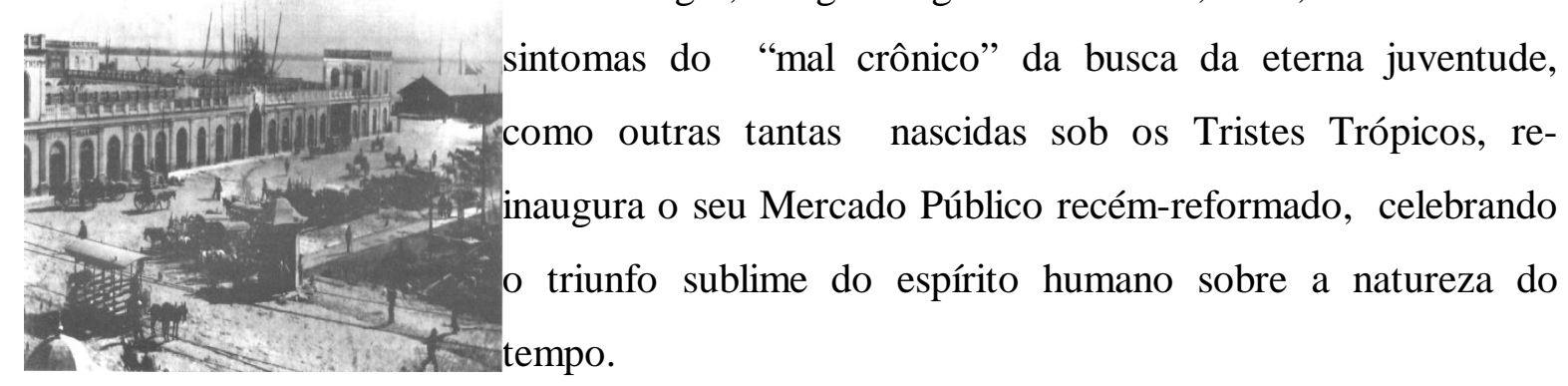

Fonte: Acervo BIEV

Fonte: Acervo BIEV

Nas trilhas de um tempo curto, e seguindo-se o ritmo da história unilateral e triunfante da modernidade, muito se tem afirmado acerca do aspecto indigente, mutante mutável dos conjuntos urbanos das cidades tropicais e da imagem da destruição que aí encerra o processo de instalação da civilização urbana.

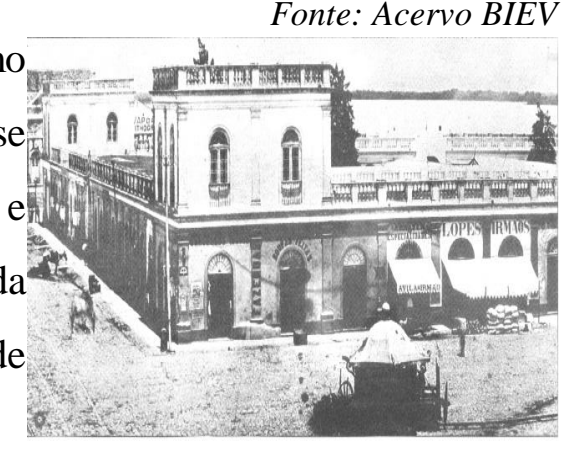

Fonte: Acervo BIEV

A meio caminho entre o natural e o artifício, a reforma pela qual passou recentemente o Mercado Público de Porto
Alegre revela quão contemporânea ainda é afirmação habitantes urbanos, o atual Mercado nos convida a pensar a figura do tempo que ele encerra.

Fonte: Acervo BIEV

As lembranças das antigas imagens do Mercado, da paisagem urbana que circundava seu território, do folclore popular acerca do lugar e da solidez material que restou de sua antiga fachada contrastam com intervenção radical 
promovida em suas ambiências internas e no território do antigo Largo, interrogando aquele que por ali passa sobre a forma complexa com que a Civilização insiste em se impor sob os Trópicos.

A figura arquitetônica do Mercado Público renasce hoje no imaginário urbano concentrando novas utopias sobre a cidade moderna e suas mutações tecnológicas.

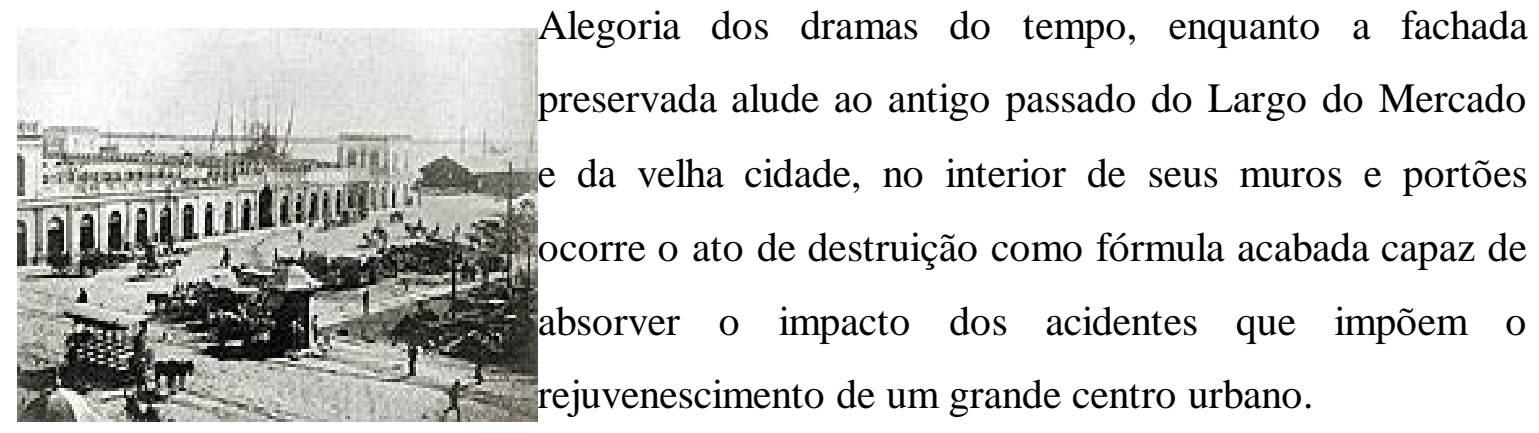

Fonte: Acervo BIEV

Fonte: Acervo BIEV

Assim é que, para manter-se perenemente jovem, cidade de Porto Alegre deve alimentar-se da substância perecível do tempo, aderindo a atos de destruição como forma de rejuvenescer. Herdeira de uma sociedade nomade e pastoril, Porto Alegre abraçou a civilização urbana a partir do ritmo agitado de queimas, destruições, perseguições,

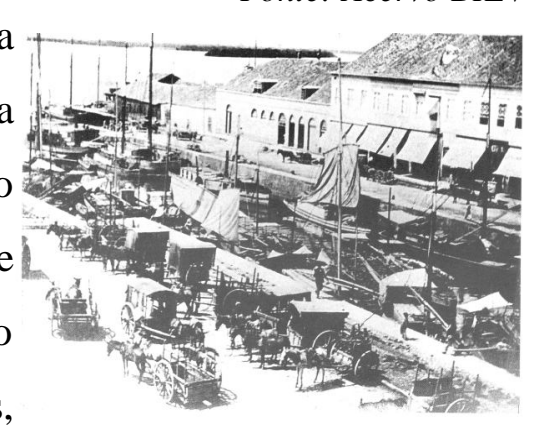
demolições e devastações de guerras e lutas no sul do Brasil, contrastando com o ritmo mais

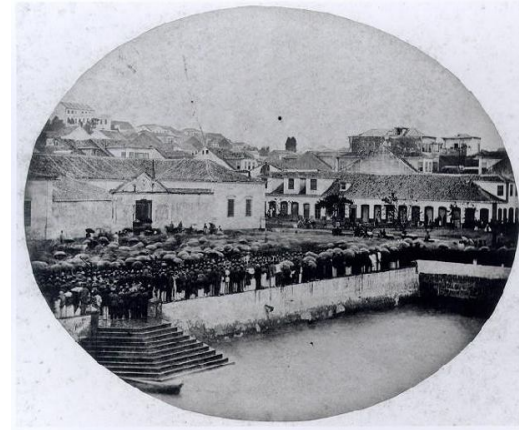

lento da acumulação de bens, de coisas, de riquezas e de homens, que caracterizou a civilização do acúcar no nordeste do Brasil. Cidade-pouso, Cidade-fortificada, Cidade-porto, Cidade-mercado, Porto Alegre refunda eternamente cidades, seguindo ainda hoje os atos de destruição que orientaram a ocupação territorial nos Trópicos.

Fonte: Acervo BIEV 
Fonte: Acervo BIEV 'As transformações no espaço interno do Mercado, a realocação e remodelação das bancas, a higienização do espaço, a inclusão aí de novas e modernas tecnologias construtivas
f)
estilo de arquitetura de shoppings centers que avança como uma nova forma de sociabilidade nas grandes metrópoles.

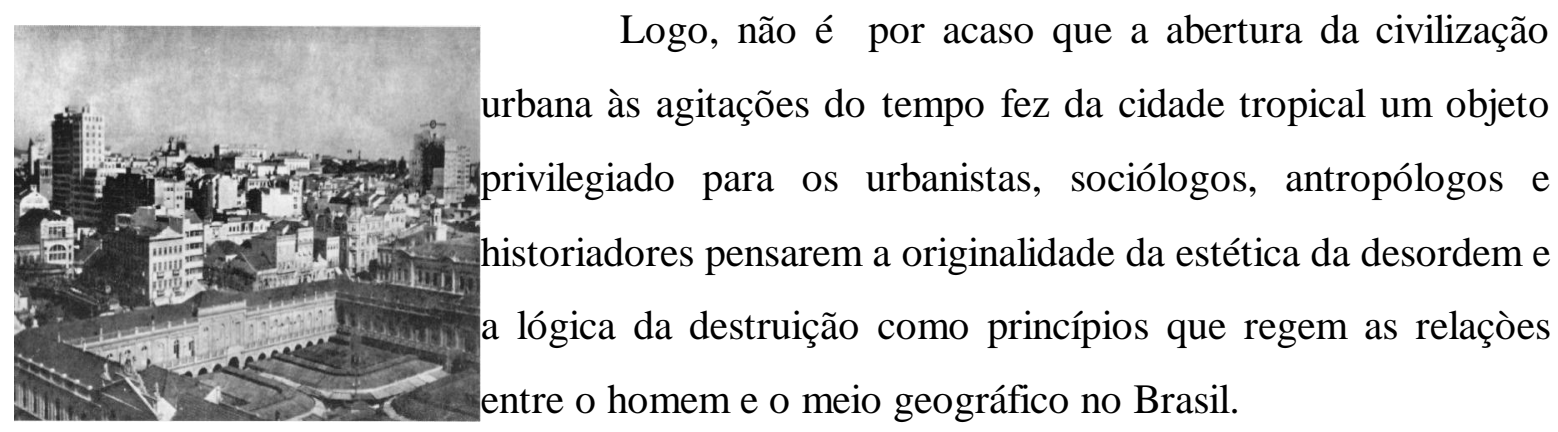

Fonte: Acervo BIEV

Entretanto, há que se confrontar essa lógica da destruição-reconstrução da Cidade com esforço dispendido por seus habitantes para acomodar, de forma duradoura, as velhas lembranças e recordações de seus antigos espaços afetivos no interior de tais transformações.

Fonte: Acervo BIEV

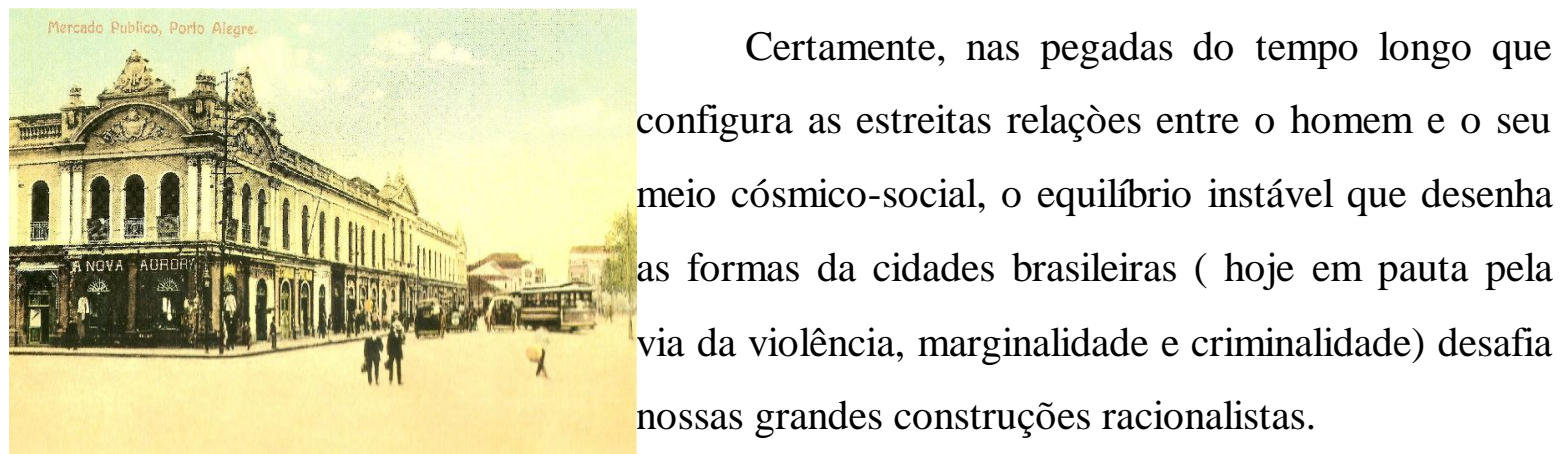


Contemplar, na reforma do Mercado Público, a força subversiva da barbárie que preside o nascimento e a morte da Cidade nos Trópicos faz com que pensemos que entre nós as cidades sofrem do "mal crônico" de serem perpetuamente jovens, enquanto em outros países do mundo elas "dormem docemente o sono da morte".

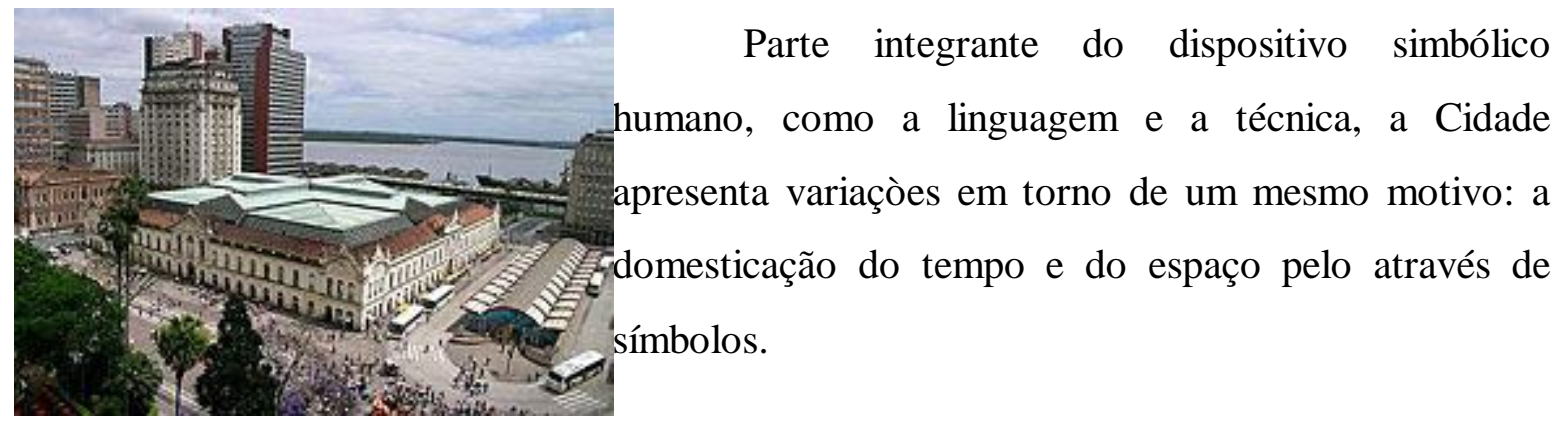

Fonte: site: pt.wikipedia.org/wiki/Porto_Alegre

Assim, se em certos centros urbanos o ato de restaurar e conservar edificações são formas encontradas por seus habitantes para domesticar a passagem do tempo, fazendo da cidade um "cemitério de civilizações", em outros, a adesão ao ritmo de inovações e modernizações impõe a destruição de antigos casarios, velhos bairros e paisagens de arrabaldes, na busca de recriar o caos primordial onde se celebra, com vigor, o renascimento de um novo corpo coletivo.

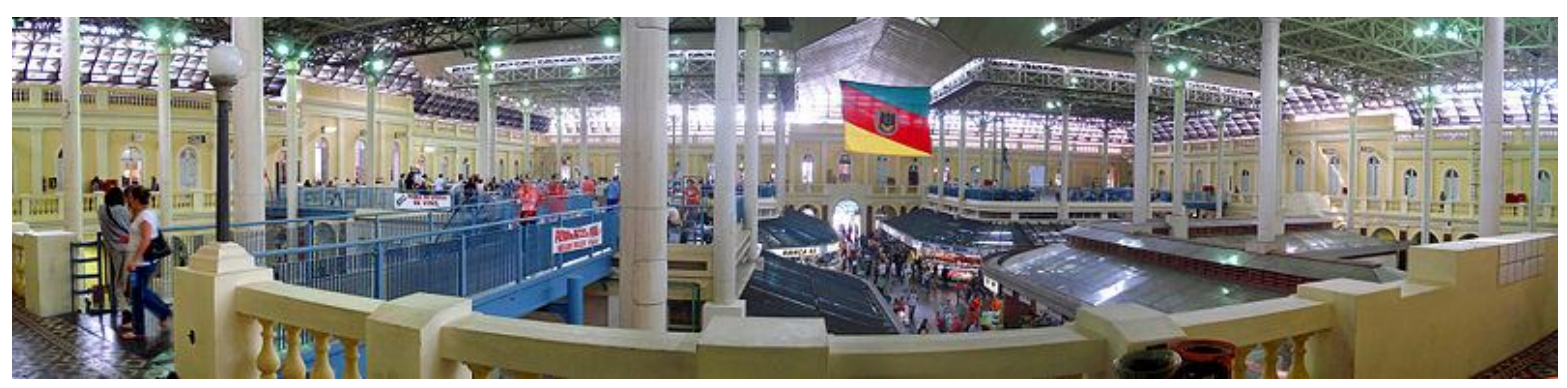

Fonte:site: pt.wikipedia.org/wiki/Porto Alegre

Na dialética temporal de vida, morte e renascimento da comunidade local, portanto, a reforma do Mercado Público pode ser vista como uma caixa de ressonância onde ecoam não apenas as lembranças e reminisciências da vida urbana da antiga Porto Alegre mas, 
principalmente, a capacidade regeneradora de um corpo coletivo na luta para vencer a matéria perecível do tempo.
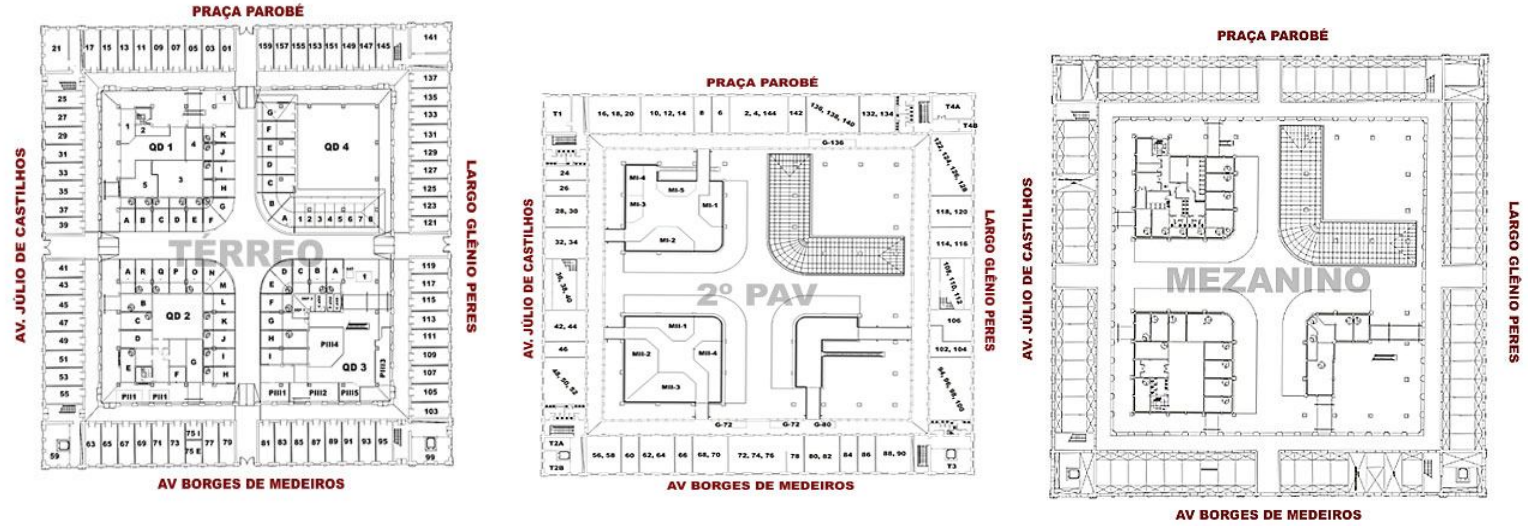

Fonte :site: pt.wikipedia.org/wiki/Porto Alegre

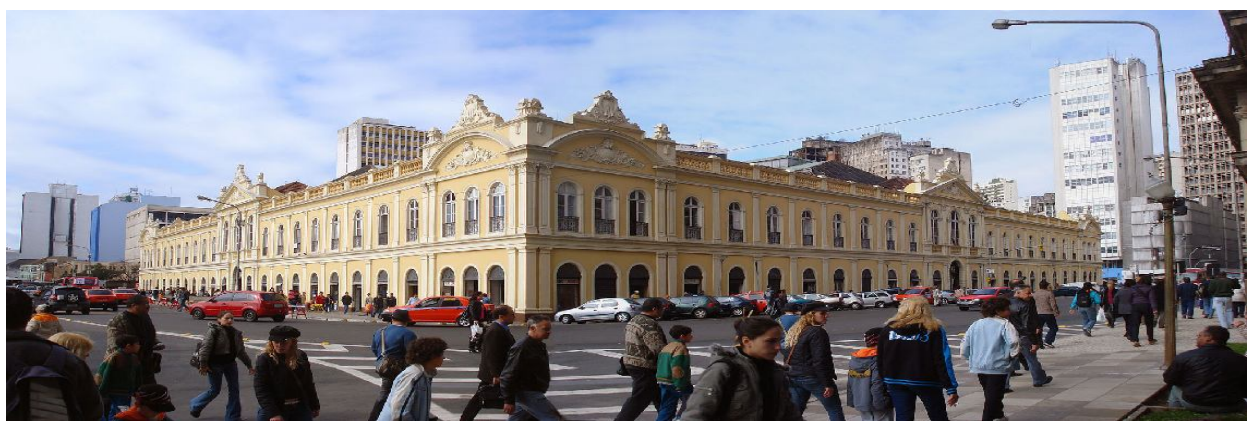

Logo, a inscrição do atual Mercado Público na memória coletiva de Porto Alegre depende, assim, menos da reforma de suas instalações do que da força poética que encerra este lugar no imaginário urbano local capaz de refundar a vida coletiva no interior de seus muros e para além de seus portões. 